\title{
ELECTROSLAG SURFACING USING DISCRETE MATERIALS OF DIFFERENT METHODS OF MANUFACTURE
}

\author{
Yu.M. KUSKOV, G.N. GORDAN, I.L. BOGAJCHUK and T.V. KAJDA \\ E.O. Paton Electric Welding Institute, NASU \\ 11 Bozhenko Str., 03680, Kiev, Ukraine. E-mail: office@paton.kiev.ua
}

\begin{abstract}
Work studies the possibility of application of waste products forming at shot production as discrete filler material in addition to shot of optimum factional composition. It is determined that surfacing by shot from high-chromium cast iron virtually has no difference on surfacing using tablets formed by powder metallurgy from shot production wastes. Metal, deposited by shot, is characterized by finer structure of structural constituents and lower quantity of austenite. Identity of surfacing results, apparently, can be achieved during optimizing the technology of tablet production, their sizes and mass rate of feeding in slag pool. 4 Ref., 2 Tables, 6 Figures.
\end{abstract}

Key words: electroslag surfacing, current-carrying mold, shot, tablets, microstructure of deposited metal

Technology of electroslag surfacing (ESS) and re-melting in current-carrying mold developed at the E.O. Paton Electric Welding Institute allows melting the compact (wires, strips, rods etc.) as well as discrete (shot, chips, powders etc.) materials in a slag pool [1].

Experience of practical surfacing [2] as well as evaluation of thermal condition of slag pool and process of melting of compact and discrete materials in it [3] allowed making a conclusion on application prospects from technical and economical point of view of electroslag process using discrete filler.

Surfacing consumable in form of shot have found the largest application in surfacing among the big list of discrete fillers. Present study compares results of surfacing made using two types of filler materials, i.e. shot and tablets. The second type is considered due to peculiarities of cast shot production.

Today, metallic shot can be manufactured by different technological schemes. The majority of widely used methods of production include the following general operations: metal melting, its dispersion, separation of scrap metal, drying, sizing for fractions, prepacking and stocking. Production of surfacing shot can additionally include magnetic separation, intersizing and vibratory cleaning. Fragmentation and sizing operations are to be entered in the case of manufacture of chipped shot.

The cheapest, easiest and widely distributed industrial method of shot manufacture is its pro-

(c) Yu.M. KUSKOV, G.N. GORDAN, I.L. BOGAJCHUK and T.V. KAJDA, 2015 duction by air atomization of molten metals [4]. Physico-Technical Institute of Metals and Alloys of the NAS of Ukraine (former Institute for Cast Problems of AS of USSR) developed technology and equipment complexes of «Grad» model for production of cast metallic shot with 400 to $6000 \mathrm{t}$ per year productivity.

Cast shot produced by this technology was mainly used in recent investigations and surfacing on practice. Wide spectrum of fractions is received in air atomization of molten metal. Thus, dispersion of jet of high-chromium cast iron, which is the most wide-spread wear-resistant surfacing material, promotes for formation of granules of the following fractional composition:

$\begin{array}{lccccc}\text { Size of granules, mm } & <0.5 & 0.5-1 & 1-3 & 3-5 & >0.5 \\ \text { Quantity of granules, \% } & 10.1 & 5.8 & 51.6 & 21.5 & 11.0\end{array}$

Relationship of fractions can be changed depending on chemical composition of material and dispersion parameters. In any case, production of shot provides for formation of large quantity of fractions which can not be used in surfacing. This is related with the fact that obtaining the quality surfacing requires application of shot with sufficiently narrow range of fractional composition. In particular, these boundaries for relatively fusible material, i.e. high-chromium cast iron, make $0.8-2.5 \mathrm{~mm}$.

Using chromium shot of $>0.8 \mathrm{~mm}$ fraction complicates its feeding in slag pool volume. Surface tension forces of molten slag pool prevents entering the fine shot particles through the slag surface film. At that, the particles are accumulated on the slag surface and form conglomerates. When mass of conglomerate exceeds resistance 


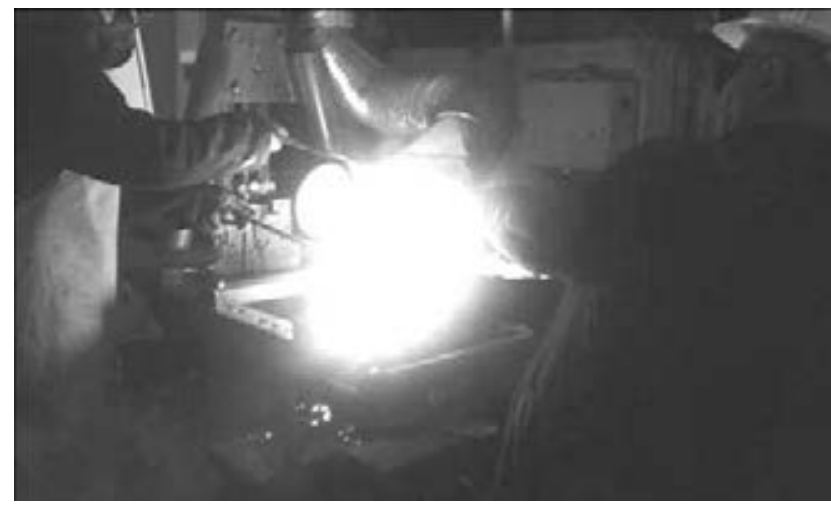

Figure 1. Filling of molten metal in current-carrying mold (using molten slag)

of surface tension forces, it penetrates in the slag volume and further in the metal pool. In this case, depending on mode of surfacing and temperature of the slag pool, it has enough time for melting or promotes formation of defects in form of pores, slag inclusions, unmelted particles of filler material.

Deposited metal can include completely unmelted granules as well as partially melted ones which form composite structure of the deposited metal in feeding to slag pool surface of particles of more than $2.5 \mathrm{~mm}$ fraction in the case of surfacing at increased mass rate of filler feeding. Such particles can also promote for formation of slag inclusions in the liquid metal.

Powder metallurgy methods can be used for solving these technological as well as economical (application in surfacing of all produced shot) task. In particular, fine fraction part of cast shot as well as coarse fraction one (preliminary transformed in split shot) can be pressed in form of tablets of specific size. Such tablets in surfacing will act as discrete material of the same chemical composition as surfacing shot.

Experimental deposits of 25-35 mm thickness layer were carried out using two types of discrete surfacing high-chromium ( $22-25 \% \mathrm{Cr}$ ) cast irons, i.e. shot and tablets, in current-conducting mold of $180 \mathrm{~mm}$ diameter for investigation of peculiarities of electroslag process and evaluation of surfacing results. Beginning of surfacing process was carried out using molten slag (flux ANF-29).

Figures 1, 2 and 3, respectively, show a moment of mold filling with molten slag, surfacing process itself with feeding of filler in the slag pool (using vibrodosimeter), as well as deposited specimen.

The following technical conditions were selected for used filler materials. The shot produced by air atomization has fractional composition of 0.8-2.5 $\mathrm{mm}$ diameter (Figure 4). The tablets were manufactured from fine fraction wastes of

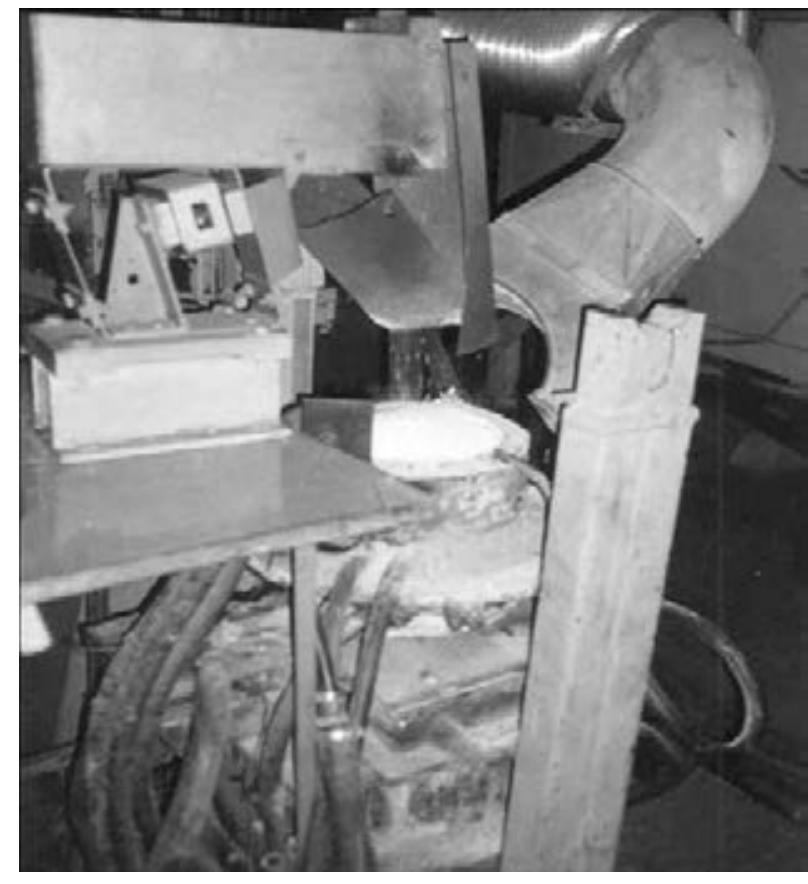

Figure 2. End surfacing of high-chromium cast iron with tablet feeding using vibrodosimeter

atomization of up to $0.4 \mathrm{~mm}$ fractional composition. Transformation of this fraction into the tablets was performed by technology applied at Brovary Plant for Powder Metallurgy (Ukraine). Bakelite lacquer was used as a plasticizing agent. Tablets of $10 \mathrm{~mm}$ diameter and 2.8-3.2 $\mathrm{mm}$ thickness were produced as a result of pressing.

Process of surfacing using both discrete materials was stable. However, some gas emission, related with burning of bakelite lacquer, was observed at tablets feeding in the slag pool. It resulted in appearance of small quantity of pores in metal deposited by tablets. Reduction of level of gas emission or its complete removal is possible at optimum selection of plasticizing agent.

Specimens for optical metallography and Xray spectrum analysis were manufactured from produced bimetallic billets by means of mechanical cutting. Examination of microstrucutres was carried out using «Neophot-32» microscope,

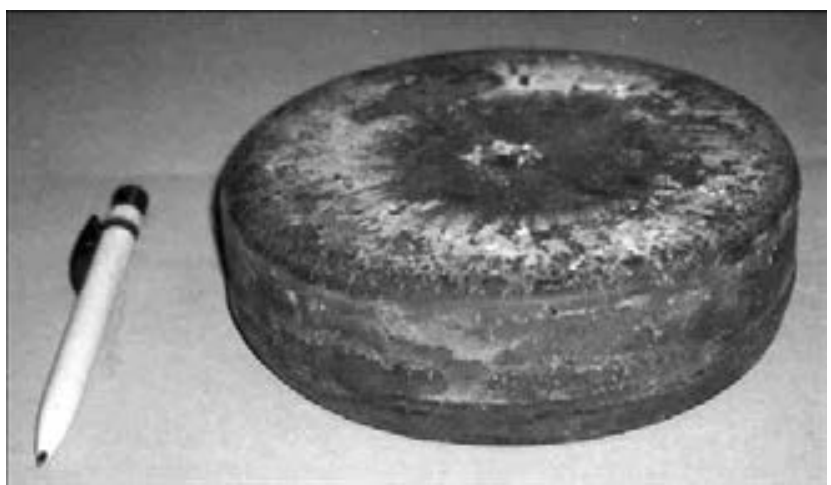

Figure 3. View of billet deposited by tablets 


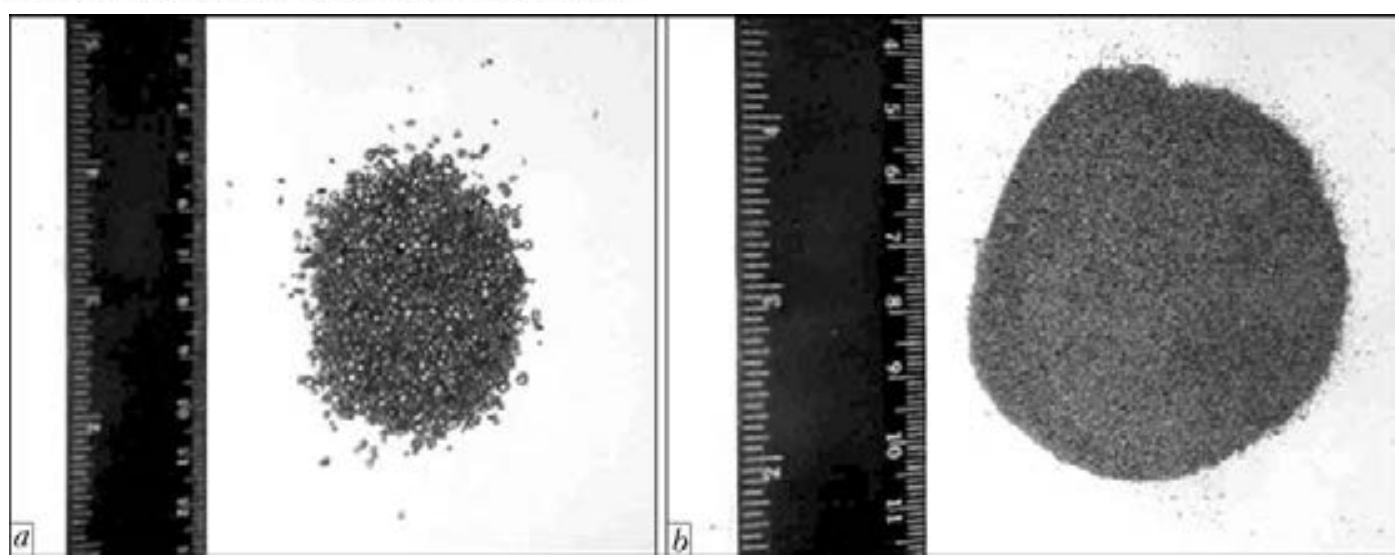

Figure 4. Discrete fillers from high-chromium cast iron: $a$ - shot produced by air atomization; $b$ - fine fraction wastes of atomization

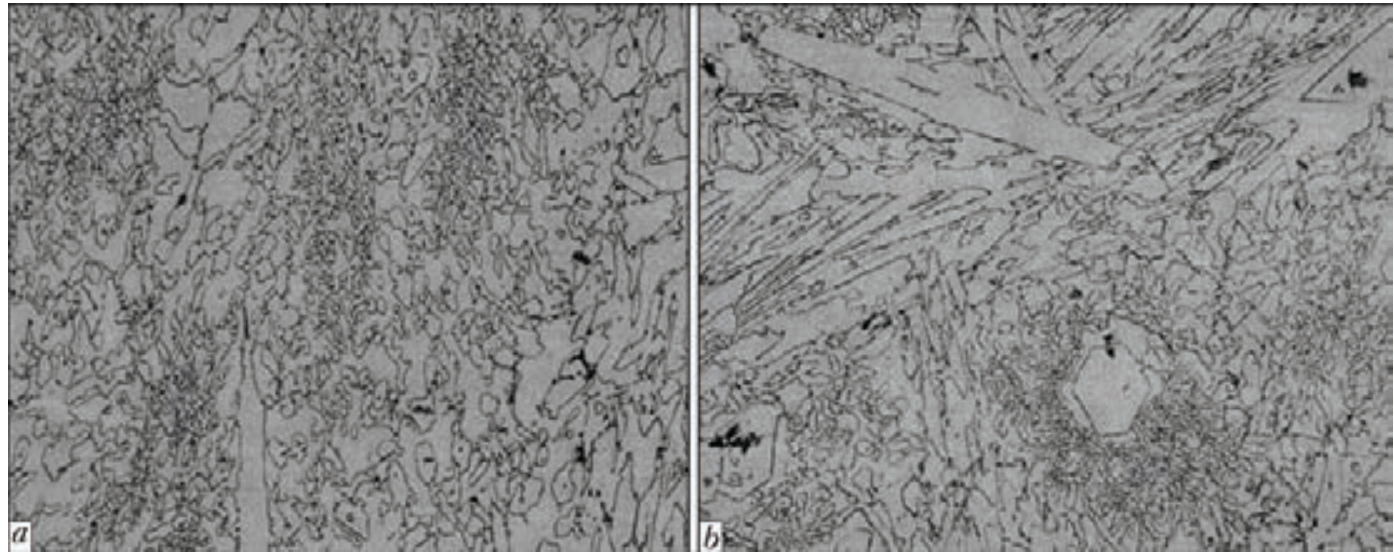

Figure 5. Microstructure $(\times 400)$ of high-chromium cast iron deposited by shot $(a)$ and tablets $(b)$

durometric measurements were performed on the LECO microhardness tester M-400, Camebax SX-50 and DRON TsUM1 were used for X-ray spectrum and X-ray structure examinations, respectively.
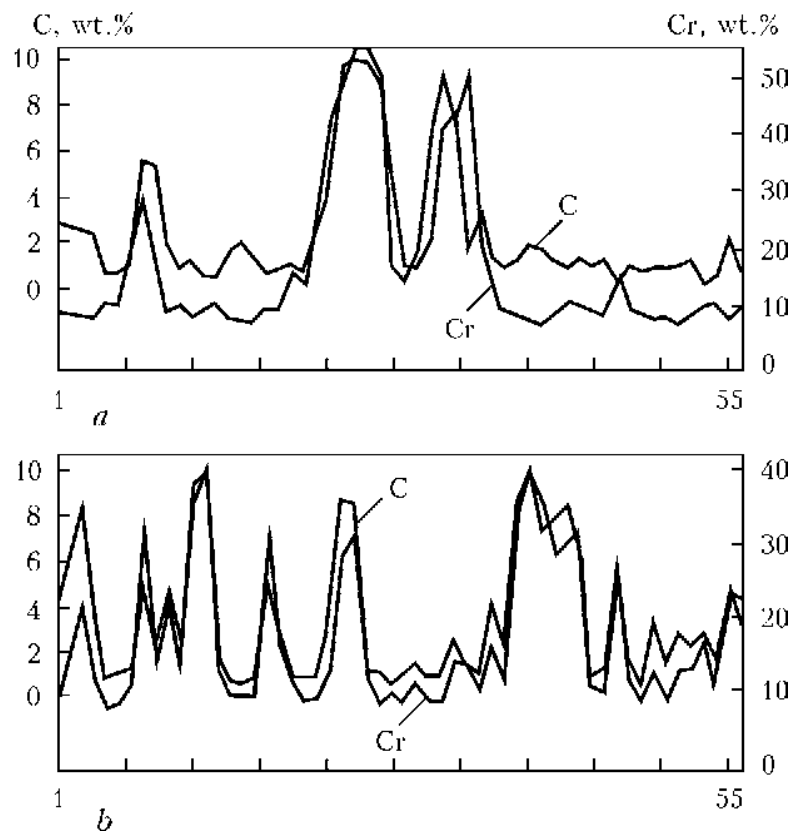

Figure 6. Results of X-ray spectrum analysis of high-chromium cast iron deposited by shot $(a)$ and tablets $(b)$
The following was determined as a result of performed examinations. Metal, deposited by shot, in comparison with metal deposited by tablets, almost does not include coarse carbides of $\mathrm{Cr}_{7} \mathrm{C}_{3}$ type and has structural constituents of

Table 1. Microhardness of structural constituents of metal deposited by shot and tablets

\begin{tabular}{|c|c|c|c|c|}
\hline \multirow{2}{*}{$\begin{array}{l}\text { Discrete } \\
\text { filler }\end{array}$} & \multicolumn{3}{|c|}{ Microhardness, MPa, at $P=0.5 \mathrm{~N}$} & \multirow{2}{*}{$\begin{array}{c}\text { Intergral } \\
\text { hardness, } \\
\mathrm{MPa} \text {, at } \\
P=10 \mathrm{~N}\end{array}$} \\
\hline & $\begin{array}{c}\text { Matrix } \\
\text { (austenite) }\end{array}$ & Carbides & Eutectic & \\
\hline Shot & $4410-5090$ & $11450-12830$ & $6180-6390$ & $5610-5810$ \\
\hline Tablets & 5980 & $12260-13370$ & 6610 & 6130 \\
\hline
\end{tabular}

Table 2. Results of X-ray structural analysis of metal deposited by shot and tablets

\begin{tabular}{|c|c|c|}
\hline \multirow{2}{*}{$\begin{array}{c}\text { Structural } \\
\text { constituents }\end{array}$} & \multicolumn{2}{|c|}{$\begin{array}{c}\text { Content (\%) of structural constituents in metal } \\
\text { deposited by }\end{array}$} \\
\cline { 2 - 3 } & Shot & Tablets \\
\hline$\gamma-\mathrm{Fe}$ & 65.63 & 80.19 \\
\hline$\alpha-\mathrm{Fe}$ & 20.97 & 8.03 \\
\hline$(\mathrm{CrFe})_{7} \mathrm{C}_{3}$ & 13.40 & 11.78 \\
\hline
\end{tabular}


smaller size, in particular, with more dispersed eutectic colonies $\left(d_{\text {shot }}=50-60 \mu \mathrm{m} ; d_{\mathrm{tab}}=80-\right.$ $90 \mu \mathrm{m}$ ) (Figure 5, $a, b$ ).

Microhardness of structural constituents of metal deposited by shot and tablets is represented in Table 1.

The following conclusions can be made based on results of X-ray spectrum analysis (Figure 6, $a, b)$. Metal structure in both cases mainly consists of austenite as well as carbides and chromium-carbide eutectics. Metal, deposited by shot, is characterized by finer atructure of structural constituents and lower amount of austenite, that is verified by results of X-ray structure analysis (Table 2).

It should be noted that observed structural differences in metal, deposited using different types of fillers, can to some extent depend on optimum selection of tablet size. The tablets of comparatively large size can result in different conditions of melting of their various parts, i.e. fusion of external part results in metal solidification similar to that taking place in melting of shots, and internal one, being a particle conglomerate, does not have enough time for melting and developing uniform heat conditions for harmonization of chemical composition in metal volume (kind of cluster). The result of such nonunifor- mity can be, for example, coarse carbide inclusions, located in separate zones of deposited metal (see Figure 5, $b$, upper part).

\section{Conclusions}

1. Experiments proved the technological and economic relevance of application of unconditioned fractions of discrete filler produced by atomization of molten metal.

2. Achievement of identity of metal microstructures deposited by shot and tablets, produced by pressing of fine fraction wastes through atomization of molten metal, requires optimizing of tablet manufacture technology as well as their sizes and, possibly, mass rate of tablet feeding to slag pool surface.

1. Kuskov, Yu.M. (2013) Electroslag surfacing in sectional current-carrying mould. Svarshchik, 3, 21-23.

2. Kuskov, Yu.M., Skorokhodov, V.N., Ryabtsev, I.A. et al. (2001) Electroslag surfacing. Moscow: Nauka i Tekhnologii.

3. Ksyondzyk, G.V., Frumin, I.I., Kuskov, Yu.M. (1977) Electroslag surfacing with grain filler material. In: Theoretical and technological principles of surfacing, 89-95. Ed. by I.I. Frumin. Kiev: PWI.

4. Zatulowsky, S.S., Mudruk, L.A. (1988) Production and application of metal shot. Moscow: Metallurgiya. 